\title{
Time-place learning over a lifetime: absence of memory loss in trained old mice
}

\author{
Cornelis K. Mulder, ${ }^{1,2}$ Gerlof A.R. Reckman, ${ }^{1}$ Menno P. Gerkema, ${ }^{2}$ and Eddy \\ A. Van der Zee ${ }^{1}$ \\ ${ }^{1}$ Department of Molecular Neurobiology, ${ }^{2}$ Department of Chronobiology, University of Groningen, 9747 AG Groningen, \\ The Netherlands
}

\begin{abstract}
Time-place learning (TPL) offers the possibility to study the functional interaction between cognition and the circadian system with aging. With TPL, animals link biological significant events with the location and the time of day. This whatwhere-when type of memory provides animals with an experience-based daily schedule. Mice were tested for TPL five times throughout their lifespan and showed (re)learning from below chance level at the age of 4, 7, 12, and 18 mo. In contrast, at the age of 22 mo these mice showed preservation of TPL memory (absence of memory loss), together with deficiencies in the ability to update time-of-day information. Conversely, the majority of untrained (naïve) mice at 17 mo of age were unable to acquire TPL, indicating that training had delayed TPL deficiencies in the mice trained over lifespan. Two out of seven naïve mice, however, compensated for correct performance loss by adapting an alternative learning strategy that is independent of the age-deteriorating circadian system and presumably less cognitively demanding. Together, these data show the age-sensitivity of TPL, and the positive effects of repeated training over a lifetime. In addition, these data shed new light on aging-related loss of behavioral flexibility to update time-of-day information.
\end{abstract}

Aging is characterized by cognitive decline (Winocur 1992; Nilsson 2003; Hedden and Gabrieli 2004; Burke and Barnes 2006), as well as circadian system deterioration (Turek et al. 1995; Van der Zee et al. 1999; Hofman and Swaab 2006; Brown et al. 2011; Kondratova and Kondratov 2012). Evidence suggests that these processes may be interrelated (Antoniadis et al. 2000; Biemans et al. 2003; Cain et al. 2004; Eckel-Mahan et al. 2008; Stranahan et al. 2008; Van der Zee et al. 2009; Kondratova et al. 2010). With time-place learning (TPL), animals link biological significant events (e.g., localizing a food source, encountering a mate or predator) with the location and time of day (TOD). This ability has been shown in many species and likely provides an evolutionary advantage by optimizing resource localization, reproductive success and predator avoidance in the natural circadian environment (Mulder et al. 2013b).

Most organisms, ranging from cyanobacteria to mammals, have evolved circadian systems to time internal physiology and behavior in daily (circadian) cycles (Panda et al. 2002; Van der Zee et al. 2009; Hut and Beersma 2011; Hut et al. 2013). Briefly, the circadian system is composed of a network of hierarchically interconnected circadian oscillators (tissues and neuronal assemblies) which drive the circadian expression of many physiological parameters. In mammals, the suprachiasmatic nucleus (SCN) is recognized as the "master clock" in the brain (Stephan and Zucker 1972; Groos and Hendriks 1982; Ralph et al. 1990). This oscillator synchronizes to the environmental light-dark (LD) cycle and in turn synchronizes many subordinate oscillators in the brain and periphery. In external $24 \mathrm{~h} \mathrm{LD}$ cycles, the circadian system provides entrained daily rhythms in the body. In constant external conditions, these circadian rhythms are maintained with an intrinsic period $(\tau)$ of about (circa-) $1 \mathrm{~d}$ (-dian). Because $\tau$ is slightly different from $24 \mathrm{~h}$ in absence of entraining external cues (zeitgebers), circadian rhythms will show a free-run pattern

\section{Corresponding author: Cornelis.mulder@rug.nl}

Article is online at http://www.learnmem.org/cgi/doi/10.1101/lm.037440. 114. in daily activity plots (actograms). On a cellular level, circadian rhythms are predominantly controlled by clock genes and their protein products, which are expressed in virtually all cells in the body. In short, CLOCK (circadian locomotor output cycles kaput) and BMAL1 (brain and muscle ARNT-like protein 1) form a heterodimeric complex which acts as a transcription activator for PER (period) and CRY (cryptochrome) proteins. PER and CRY proteins dimerize and translocate back into the nucleus to inhibit the CLOCK-BMAL1 transcription factor, forming a closed transcriptional-translational feedback loop (for review, see Dibner et al. 2010).

Aging is accompanied by severe circadian system deterioration, as is evidenced by manifold changes in behavior and physiology. One of the most consistent findings in aged individuals is a dampening of amplitude, which applies to overt activity rhythms, physiological parameters (such as body temperature), hormone levels, SCN neuronal firing rate, and SCN peptidergic output. Other hallmarks are an increased fragmentation of rhythms, extended activity periods, changes in free-running period, disturbed sleep-wake rhythms, altered phase relationships, and changes in the ability to synchronize to zeitgebers (for review, see Van Someren et al. 1999; Weinert 2000). Recent studies have indicated that the circadian system supports temporally regulated events underlying memory processes, such as acquisition, consolidation, and retrieval (Eckel-Mahan and Storm 2009; Gerstner et al. 2009; Gerstner and Yin 2010; Jilg et al. 2010; Kondratova et al. 2010; Rawashdeh and Stehle 2010). It has been proposed that the aging-related flattening of circadian rhythms is causally linked to hippocampal neuropathology (Stranahan et al. 2008; Kondratova and Kondratov 2012).

\footnotetext{
(C) 2015 Mulder et al. This article is distributed exclusively by Cold Spring Harbor Laboratory Press for the first 12 months after the full-issue publication date (see http://learnmem.cshlp.org/site/misc/terms.xhtml). After 12 months, it is available under a Creative Commons License (AttributionNonCommercial 4.0 International), as described at http://creativecommons. org/licenses/by-nc/4.0/.
} 
TPL enables the investigation of a specific role of the circadian system in learning and memory. Besides governing innate rhythms in physiology and behavior, it is believed that circadian oscillators can be used as a consulted clock and provide TOD information to brain systems involved in cognitive tasks, like TPL (Enright 1970; Gallistel 1990; Mistlberger et al. 1996; Hut and Van der Zee 2011). According to this hypothesis, a circadian clock (-system) is continuously consulted. On the occurrence of biological significant events, TOD derived from this clock is stored into memory as a contextual cue (referred to as a time stamp) and associated with place- and event-specific information to guide future behavior. In addition to circadian system involvement, TPL is likely hippocampus-dependent as it involves memories for spatial representations and "what-where-when" associations over time (Stranahan et al. 2008). Hippocampus-dependent associative (episodic-like) memory is particularly age-sensitive, as opposed to for instance procedural (implicit) memory (Newman and Kaszniak 2000; Fleischman et al. 2004). Hence, TPL offers the opportunity to study the functional interaction of these systems with aging, as opposed to the more reductionist approach of studying these systems separately.

To fully appreciate the underlying components of TPL, it is important to explain the different strategies an animal can use to cope with events which occur predictably at specific TODs. In laboratory TPL studies, animals are typically tested at multiple fixed times of the day (daily test sessions). They are trained over multiple days to show a session-specific response (visiting/avoiding specific locations). Testing procedures need to be kept exactly the same for each test session so that TOD is the only predictor for the correct locations. Several strategies have been identified for animals to solve such a task: ordinal timing, interval timing, or using an internal circadian clock (Carr and Wilkie 1997). With ordinal timing, the animal remembers the sequence of events (e.g., first test session, avoid location A; second test session, avoid location $B$, etc.). If this strategy is used, then performance will drop below chance level after a session is skipped. With interval timing, an animal tracks or estimates the passage of time relative to a stable external time cue (zeitgeber). This strategy may be applied if animals learn to associate intervals with a specific feeding location, e.g., shortly after light onset (first test session), avoid location A; longer after light onset (second test session), avoid location $B$, etc. We refer to these strategies as noncircadian or external-cue-based strategies. Alternatively, animals must use a circadian strategy when above chance level TPL performance is maintained in constant (zeitgeber deprived) conditions and after session skips. In that case, animals must use an internal conception of TOD, independent of external cues. The circadian strategy is theoretically the most reliable strategy because it does not depend on external cues which can be unreliable or remain unnoticed. However, animals do not readily use this strategy unless properly motivated. The circadian strategy and the formation of TOD integrated (what-where-when associated) memory may thus be more demanding on brain resources to form and/or maintain, and therefore, only be used when learning a time-place contingency is important for well-being or survival (Mulder et al. 2013b). While TPL refers to the behavioral output of visiting correct locations at the correct TOD (using any possible strategy), we refer to circadian TPL (cTPL) when the use of a circadian strategy is confirmed or implied.

cTPL has been demonstrated in several studies (Biebach 1989; Wenger et al. 1991; Falk 1992; Saksida and Wilkie
1994; Mistlberger et al. 1996; Pizzo and Crystal 2002), while others either failed to show TPL or found that animals used a noncircadian strategy to solve the task (Carr and Wilkie 1997, 1999; Carr et al. 1999; Pizzo and Crystal 2002, 2004; Thorpe et al. 2003). Whether an animal is capable of mastering a TPL task may depend on the species or used strain, but is also greatly determined by the experimental setup (see Mulder et al. 2013b). Previously, we designed a now well-established TPL paradigm for mice based on a balanced approach between reward and punishment (Van der Zee et al. 2008). Mice are food deprived to $85 \%$ of ad libitum body weight. Correct location choices are rewarded by food, while incorrect location choices result in a penalty in the form of a mild footshock. This paradigm emulates the natural situation in which hungry animals seek food while different feeding locations can be predictably safe or unsafe to visit depending on the TOD. We have shown repeatedly that young wild-type mice readily acquire this paradigm and will structurally use a circadian strategy (Van der Zee et al. 2008; Mulder et al. 2013a, 2014).

TPL has not been investigated before in the context of aging. Here we set out to investigate TPL ability over the lifespan, together with spatial working memory performance and circadian activity parameters. As a circadian system and hippocampusdependent learning task, we hypothesized that (c)TPL is particularly age-sensitive.

\section{Results}

\section{TPL in mice trained over lifespan}

Mice were tested at $4,7,12,18$, and 22 mo of age. A schematic overview of the daily TPL testing protocol is provided in Figure 1 , and described in more detail in the Materials and Methods section. At each age, TPL testing started while the animals were housed in LD, followed by a period of testing while the animals were housed in LL. Only at 12 mo of age, mice were housed (and tested) in DD to investigate whether mice would react differently (in DD, mice are known to establish a shorter $\tau$ than in LL). However, no differences were found in TPL behavior between the LL and DD conditions. Different sessions were skipped regularly to ensure that the mice used a circadian strategy.

Baseline performance is defined as performance on all "normal" test days (without session skips or other manipulations), excluding the first $4 \mathrm{~d}$ during which the learning curve is typically formed (except at 22 mo of age, where a learning curve was absent). Results of average baseline performances and average performances after session skips (measured in the single next session after the skipped session) are summarized in Table 1, together with a statistical evaluation (two-tailed one-sample $t$-tests) compared with the $33.3 \%$ chance level. The number of subjects $(N)$ is decreased at the higher ages due to aging-related drop-out (mice that appeared weak were not used for testing). Although we started with $N=9$, one mouse was excluded because it never 
Table 1. TPL baseline performance and performance after session skips, in LD and constant lighting conditions

\begin{tabular}{|c|c|c|c|c|c|c|c|c|c|c|c|c|c|}
\hline \multirow{3}{*}{ Age $(\mathrm{mo})$} & \multirow{3}{*}{$N$} & \multicolumn{6}{|c|}{ Baseline TPL performance } & \multicolumn{6}{|c|}{ TPL performance after session skips } \\
\hline & & \multicolumn{3}{|c|}{ LD } & \multicolumn{3}{|c|}{ LL } & \multicolumn{3}{|c|}{ LD } & \multicolumn{3}{|c|}{ LL } \\
\hline & & $\mathrm{d}$ & $\%$ (SEM) & $P$-value & days & $\%$ (SEM) & $P$-value & \# & $\%$ (SEM) & $P$-value & \# & $\%$ (SEM) & $P$-value \\
\hline 4 & 8 & 15 & $87(3)$ & $<0.001$ & 7 & $82(4)$ & $<0.001$ & 4 & $84(7)$ & $<0.001$ & 3 & $96(4)$ & $<0.001$ \\
\hline 7 & 8 & 2 & $83(4)$ & $<0.001$ & 1 & $83(6)$ & $<0.001$ & - & - & - & 1 & $88(13)$ & 0.003 \\
\hline 12 & 8 & 19 & $80(6)$ & $<0.001$ & $9^{a}$ & $89(4)^{a}$ & $<0.001^{\mathrm{a}}$ & 4 & $94(4)$ & $<0.001$ & $2^{\mathrm{a}}$ & $71(10)^{a}$ & $0.009^{\mathrm{a}}$ \\
\hline 18 & 6 & 11 & $84(5)$ & $<0.001$ & 6 & $86(5)$ & $<0.001$ & 2 & $100(0)$ & n.v. & 1 & $100(0)$ & n.v. \\
\hline 22 & 4 & 9 & $82(5)$ & 0.002 & 9 & $47(14)$ & 0.39 & 1 & $100(0)$ & n.v. & 1 & $75(25)$ & 0.19 \\
\hline
\end{tabular}

(\#) Number of session skips, (n.v.) no variation.

${ }^{a}$ Animals tested in DD instead of $L L$, and $N=7$.

learned to master TPL. The results show that mice are able to master TPL until the age of $18 \mathrm{mo}$, reaching a high (significantly above chance level) baseline performance in $\mathrm{LD}$, as well as when housed in constant conditions. Session skipping did not significantly affect performance, indicating that the mice kept using a circadian strategy. Aging effects start to occur at the age of 22 mo.

In Figure 2A, the bar graphs on the left show TPL performance during the three habituation steps that preceded actual TPL testing at age 4 mo (not repeated at later ages). During the first habituation step ( $\mathrm{H} 1,4 \mathrm{~d}$ ), mice could freely explore the three baited locations. No significant preference for a single (first choice) location was found $\left(\chi^{2}: P=0.25\right)$ and performance was not significantly above chance level (one-sample $t$-test: $P=$ 0.77). During the second habituation step (H2, $3 \mathrm{~d}$, test situation with target locations baited; nontarget location unbaited without footshock delivery), performance was not significantly above chance level (one-sample $t$-test: $P=0.42$ ), indicating that the mice did not show TPL without the negative reinforcer (footshock). During the third habituation step (H3, 3 d, test situation with target locations baited; nontarget location unbaited with footshock delivery), mice significantly learned to avoid the nontarget location, showing performance significantly above chance level $(P=0.0002)$. High performance is common in the third habituation step because mice can identify the nontarget/target location(s) based on sensory perception of the absence/presence of food. After these habituation steps, actual TPL testing was commenced with all locations baited, while one of the locations was negatively enforced by a footshock depending on the time of day (as schematically represented in Fig. 1).

Next to the bar graphs, Figure 2A shows TPL performance at ages 4,7 , and 12 mo over the first $7 \mathrm{~d}$ of testing in LD (gray areas), followed by the first $4 \mathrm{~d}$ of testing in absence of an LD cycle (white areas). Similarly, TPL performance at ages 18 and 22 mo are shown in Figure 2 B,C, respectively. Learning curves were formed mainly over the first $6 \mathrm{~d}$ in $\mathrm{LD}$ and found to be similar between ages $4,7,12$, and 18 mo (two-way RM ANOVA; effect of days: $F=29.16$, DF $=5, P<0.0001$; no effect of age: $F=2.03$, $\mathrm{DF}=3, P=0.13$; no interaction effect: $P=0.14)$. Bonferroni posttests showed no significant differences between these ages on any of the days ( $P>0.05$ on each day). Because of this statistical similarity, TPL performances at ages 4,7 , and 12 mo were pooled. Comparing all learning curves, including the learning curve of the mice at 22 mo of age, reveals a significant interaction effect (two-way RM ANOVA, $P=0.002$ ), indicating that the learning curve at the age of $22 \mathrm{mo}$ is different. Bonferroni post-tests showed that performance of the 22-mo-old mice was significantly different from all other ages at the first day $(P<0.001$ for each comparison). No differences between ages were found on following days, except on day 2 (age: 22 mo versus $7 \mathrm{mo}, P<0.001$ ).

No TPL aging effects were found before the age of $22 \mathrm{mo}$. At 18 mo of age the mice did show a small (not significant) drop in performance when switched to LL (Fig. 2B, day 23), but performance quickly recovered. Interestingly, at the age of $22 \mathrm{mo}$, a learning curve was absent even though mice showed high performance in LD (Fig. 2C, LD1) and performed flawlessly after a session skip (Table 1). Moreover, performance gradually decreased to below chance level after switching to LL (Fig. 2C, LL1). To investigate this more thoroughly, mice were put back on LD for $3 \mathrm{~d}$ and then on LL again. Performance was immediately recovered in LD (Fig. 2C, LD2), but again gradually dropped to below chance level in LL (Fig. 2C, LL2), confirming the previous result. A session was skipped on day 18, when performance was still high in the second LL period (Fig. 2C, LL2). Three of the four mice made correct location choices (Table 1). Although these results have limited statistical power, they suggest that the mice maintained a circadian strategy. Notably, at all ages mice did not perform better (or worse) in any specific test session.

\section{TPL in naïve mice at the age of $17 \mathrm{mo}$}

We showed that trained mice were able to show unaffected TPL until the relatively high age of 18 mo. To investigate whether this was due to a training effect, we next investigated whether untrained (naïve) 17-mo-old mice were able to acquire TPL. TPL testing was preceded by the previously described habituation steps. Results are shown in Figure 3A. During the first habituation step (H1, 4 d), mice could freely explore the three baited locations. No significant preference for a single (first choice) location was found $\left(\chi^{2} P=0.52\right)$ and performance was not significantly above chance level (one-sample $t$-test: $P=0.84$ ). During the second habituation step (H2, 3 d, test situation with target locations baited; nontarget location unbaited without footshock delivery), performance was not significantly above chance level (one-sample $t$-test: $P=0.63$ ), indicating that the mice do not show TPL without the negative reinforcer (footshock). During the third habituation step (H3, 3 d, test situation with target locations baited; nontarget location unbaited with footshock delivery), performance was not significantly above chance level (one-sample $t$-test: $P=0.20)$. The results of the first two habituation steps are typical, and similar to the 4-mo-old mice (Fig. 2A). However, the relatively low performance in the third habituation step is uncommon (because mice can identify the nontarget/target location(s) based on sensory perception of the absence/presence of food) and significantly different from the young mice (two-tailed unpaired $t$-test: $P=0.01$ ). This indicates that these mice may have had a reduced ability to identify the nontarget location based on sensory perception.

The naïve middle-aged mice were generally unable to acquire TPL (Fig. 3A "all"). Performance did not significantly exceed chance level on any day after 2 wk of daily testing (one-sample $t$-test, $P>0.1$ for all days). Only two mice reached average performance above chance level (Fig. 3A "responders"). Although these 
Time-Place Learning over lifespan
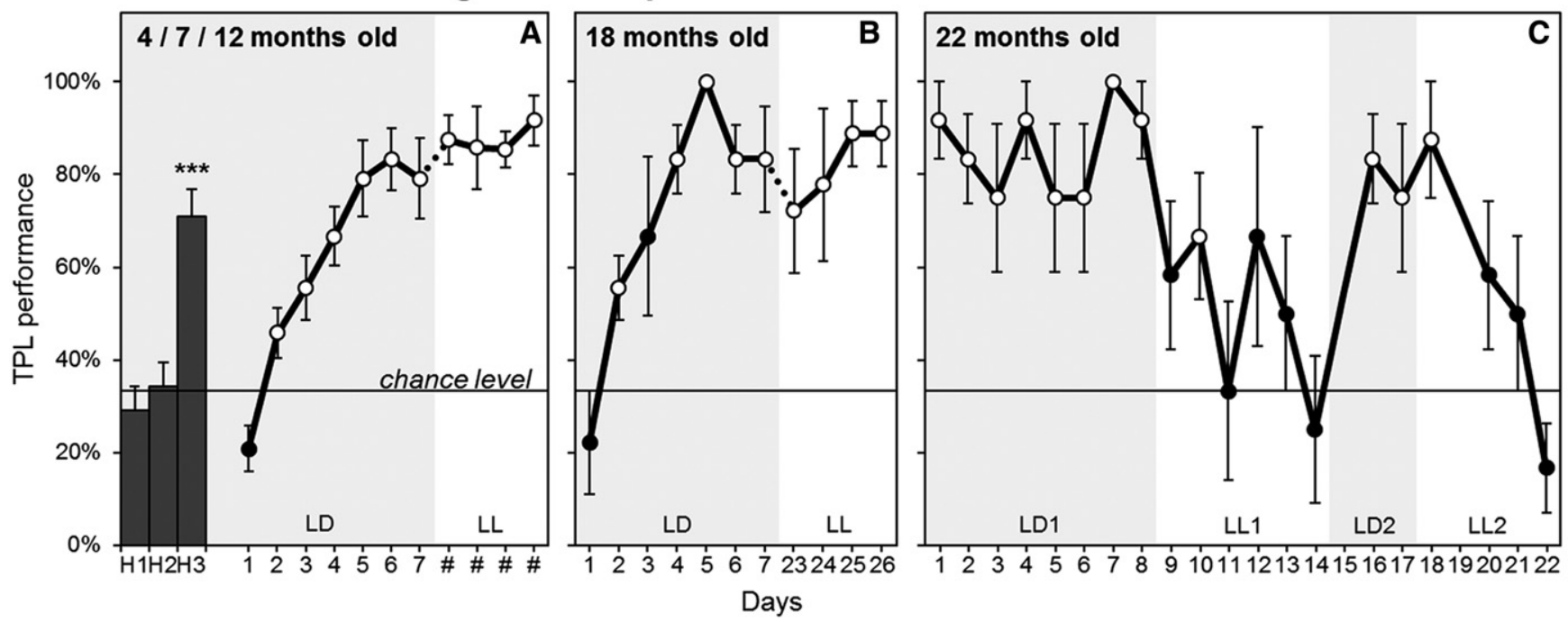

Figure 2. Time-place learning over lifespan. $(A)$ The bar graphs on the left show performance during the three habituation steps that preceded actual TPL testing at age $4 \mathrm{mo}$ (not repeated at later ages). (***) indicates performance significantly above chance level $(P<0.001)$. Next, average daily TPL performance, pooled for ages 4, 7, and $12 \mathrm{mo}$, is plotted for the first week in LD (gray areas), and followed by the first $4 \mathrm{~d}$ in LL (white areas). LL days differ between the ages and are therefore indicated by "\#" on the $x$-axis. $(B, C)$ The same format is applied for ages 18 and 22 mo, respectively. The dotted graph lines in $(A, B)$ indicate nonconsecutive days. The different $L D$ and $L L$ periods in $(C)$ are numbered for easy referencing. In all panels, the $33 \%$ chance level is indicated by the horizontal black line. Error bars represent SEM. Open data points indicate performance significantly above chance level (one-sample $t$-test for above chance level performance, $P<0.05$ ).

mice consistently showed above chance level performance over multiple days, the low sample size restricts comparisons with chance level, and other statistics should merely serve a supportive function. Nevertheless, the performance curve of the responders differed significantly from the nonresponders (i.e., "all" without the responders) (two-way RM ANOVA; effect of groups: $F=$ $37.84, \mathrm{DF}=1, P=0.002)$. Bonferroni post-tests showed that the curves were significantly different $(P<0.05)$ on days $7,10,12$, and 14. Figure 3B shows the average TPL performance before and after session skips. Performance after session skips was measured in the single next session following the skipped session. Performance before session skips was measured in the same session on the previous day. These results show that the mice generally made incorrect location choices after session skips (Fig. 3B "all"), resulting in performance significantly below chance level (one-sample $t$-test, before: $P=$ 0.56 , after: $P=0.01$ ). Performance before session skips was significantly different between the responders and the nonresponders (two-tailed unpaired $t$-test: $P=$ 0.002). Notably, performance of the responders also dropped below chance level after session skips (performance before versus after session skips, two-tailed paired $t$-test: $P=0.01$ ), indicating that these mice had adopted an ordinal strategy instead of a circadian strategy.

Spatial working memory and aging To investigate whether the TPL deficiencies observed in trained 22-mo-old mice and in naïve 17 -mo-old mice can be (partly) attributed to reduced spatial working memory abilities, the spon- taneous alternation (SA) test was performed before each TPL test. The test is based on the natural tendency of mice to inspect relatively novel locations (visited the longest time ago), typically resulting in sequential visits of the three different Y-maze locations (alternations). The alternation percentage is therefore an established measure for spatial working memory, on which the mice rely to distinguish between locations. The number of Y-maze arm entries during the 8-min test sessions is a measure for exploratory behavior. Results are shown in Figure 4.

Comparing SA performances of the trained mice at the different ages $4,7,12,18$, and 22 mo revealed no significant differences (One-way RM ANOVA: $F=1.08, \mathrm{DF}=4, P=0.39$ ). Comparing
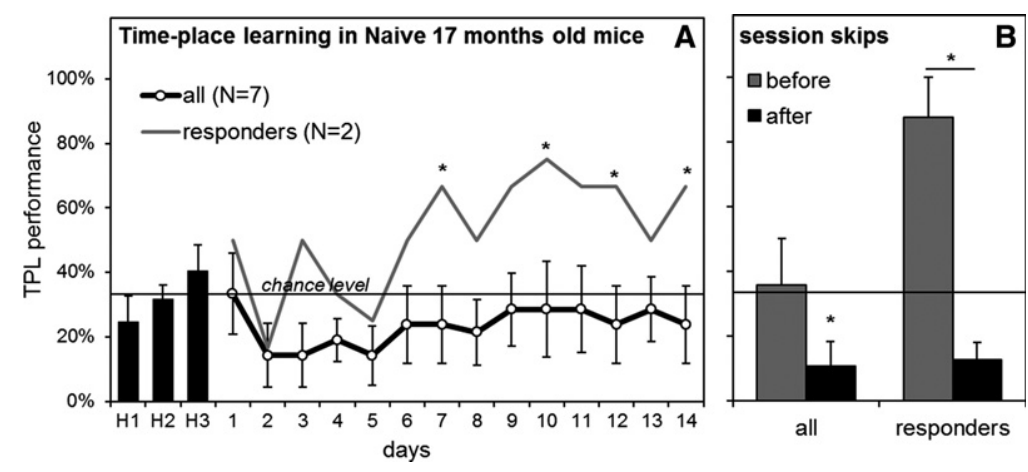

Figure 3. Time-place learning in naïve 17-mo-old mice. $(A)$ The daily performance curve over 2 wk of testing in LD (black line graph), together with a separate performance curve of two "responders." Days on which a significant difference was found between the responders and nonresponders are indicated $\left(^{*}\right)$. The bar graphs on the left show average performance during the three habituation steps that preceded TPL testing. (B) Performance before and after session skips. Performance "after" session skips was measured in the single next session following the skipped session. Performance "before" session skips was measured in the same session on the previous day. The mice performed significantly below chance level after session skips. Performance of the responders differed significantly before versus after session skips. The horizontal line indicates chance level. Error bars represent SEM. 

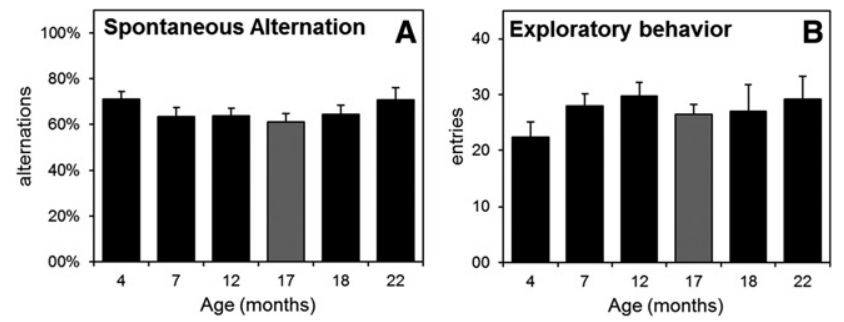

Figure 4. Spontaneous alternation results of the mice trained over lifespan at ages 4, 7, 12, 18, and 22 mo (black bars) and naïve 17-mo-old mice (gray bars). ( $A$ ) The percentage of alternations, a measure for shortterm spatial memory. (B) The number of Y-maze arm entries during the 8-min test sessions, as a measure for exploratory behavior. No statistical differences were found between any of the groups. Error bars represent SEM.

the number of entries also revealed no significant differences (One-way RM ANOVA: $F=1.14, \mathrm{DF}=4, P=0.36$ ). Separately comparing SA performances of the naïve 17-mo-old mice to all other ages of the repeatedly trained mice revealed no significant differences (One-way ANOVA: $F=1.12, \mathrm{DF}=5, P=0.37$ ). Multiple comparisons post-tests (Holm-Sidak method) showed no significant differences between the 17 -mo-old naïve mice compared with all other ages of the repeatedly trained mice $(P=0.91$ compared with the 18-mo-old trained mice, which constitute the most appropriate control). Comparing the number of entries of the naïve 17 -mo-old mice to all other ages of the repeatedly trained mice also revealed no significant differences (One-way ANOVA: $F=0.75, \mathrm{DF}=5, P=0.59$ ). Finally, multiple comparisons post-tests revealed no significant differences between the 17-mo-old naïve mice compared with all other ages of the repeatedly trained mice $(P=0.92$ compared with the 18 -mo-old trained mice).

\section{Circadian rhythm parameters with aging}

Running-wheel activity was recorded continuously over the lifespan of the TPL-trained mice. Figure 5A shows an average double plotted actogram of all mice trained over lifespan, with higher intensity gray values representing more activity. The vertical bar on the right profides an experimental overview, indicating the different housing conditions (gray $=\mathrm{LD}$, white $=\mathrm{LL}$, black $=\mathrm{DD}$ ). Black vertical lines on the right side of the bar indicate the periods during which the animals were TPL tested (and food deprived). During TPL testing, animals show food anticipatory behavior before 5:30 p.m., when food was provided daily (Fig. 1), and freerunning activity patterns in absence of an LD cycle. Twenty LD periods, or data "blocks" (distributed over lifespan, when animals were not TPL tested) of $15 \mathrm{~d}$ each, were analyzed for several established parameters that quantitatively describe circadian rhythms: daily activity, fragmentation, interdaily stability, signal-to-noise ratio, and amplitude. Similarly, five LL blocks of, respectively, $15,12,11,15$, and $12 \mathrm{~d}$ were analyzed for intrinsic
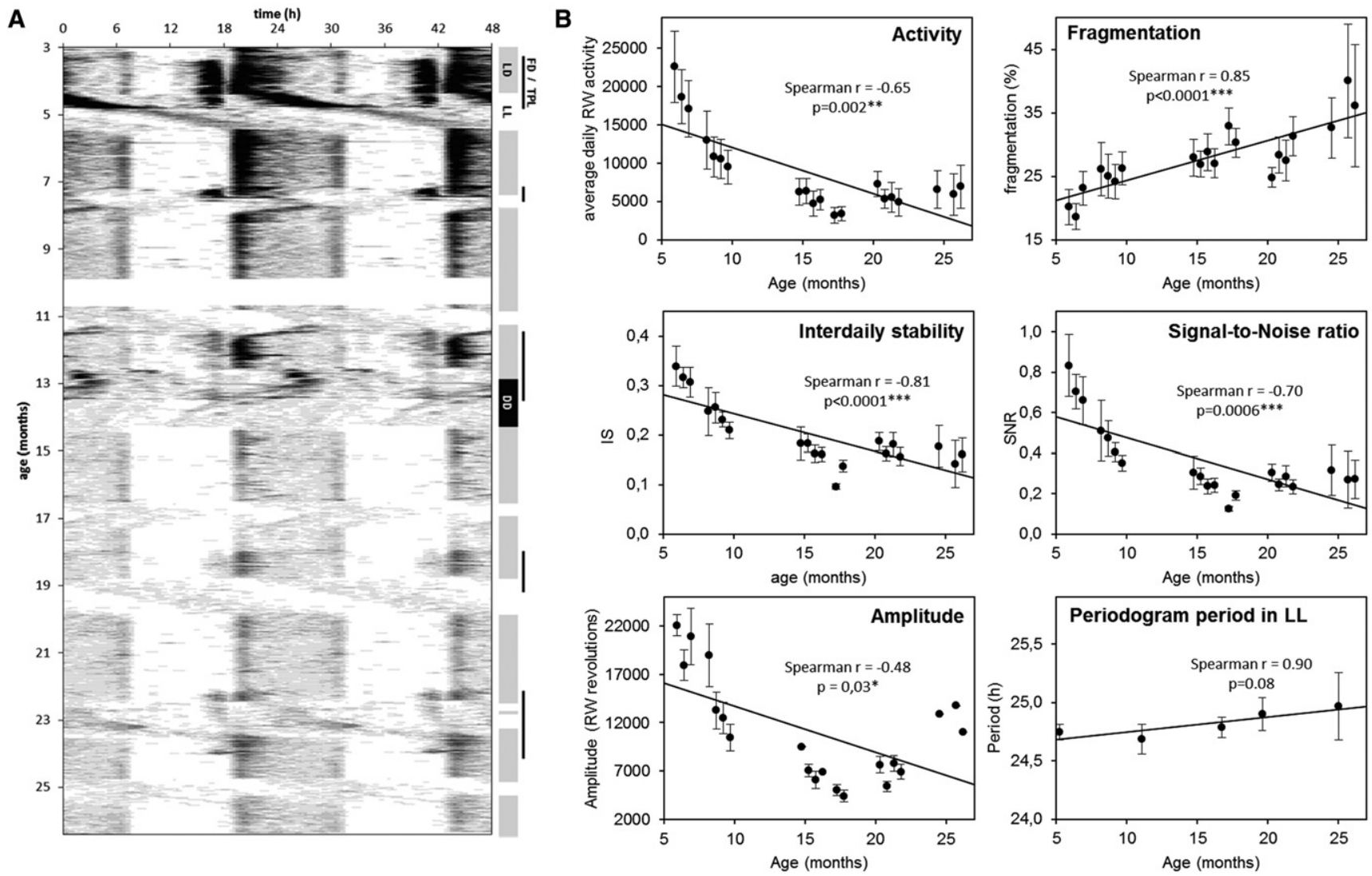

Figure 5. Analysis of circadian rhythm parameters with aging. (A) A combined (averaged) double plotted actogram of all mice trained over lifespan. Age in months is indicated on the vertical axis, time of day on the horizontal axis. The vertical resolution is $1 \mathrm{~d}$; the horizontal resolution is 10 min. Higher intensities of gray indicate more running-wheel activity. Data recording failed for a period $\sim 10$ mo of age. The vertical bar on the right indicates the different housing conditions ( $g r a y=L D$, white $=L L$, black $=D D$ ). Black vertical lines on the right side of the bar indicate the periods during which the animals were TPL tested and food deprived (FD). LD and LL periods during which the animals were not TPL tested were analyzed. (B) The results of the different parameters that were analyzed. Error bars represent SEM. 
circadian period $(\tau)$ by $\chi^{2}$ periodogram analysis. Results are shown in Figure 5B. Most of the analyzed parameters decrease with age, while fragmentation increases with age. $\tau$ measured in LL showed a slight increase with age, but not significantly. Together, these results demonstrate severe deterioration of circadian rhythmicity with aging. Notably, for most of the analyzed parameters a platform of decline is reached around the age of 17-18 mo.

\section{Discussion}

Previously, we showed that mice can use an internal circadian clock for TPL (referred to as CTPL). Because both memory function and circadian rhythms deteriorate with age, cTPL has potential as a sensitive model for aging and neurodegenerative disease. Here we investigated TPL for the first time in the context of aging. Mice were longitudinally tested at 4, 7, and 12 mo of age (here referred to as adult), $18 \mathrm{mo}$ of age (here referred to as middle-aged), and 22 mo of age (here referred to as old). In addition, 17-mo-old naïve mice (referred to as untrained middle-aged) were tested. We showed that in trained mice CTPL deficiencies occurred at old age. Conversely, untrained mice were unable to master cTPL at middleage. Some of these mice however showed TPL using a noncircadian (ordinal) strategy. Below we discuss the specific aging-related TPL deficiencies observed and their implications.

\section{Repeated training from young-adult age delays TPL deficiencies at old age}

Trained mice showed unaffected cTPL at middle-age, while untrained mice were unable to acquire (c)TPL at this age. This observation corroborates longitudinal training studies in rats showing that previous testing prevents the age-related decline in cognitive functions (van Groen et al. 2002; Blokland et al. 2004; Hansalik et al. 2006). Besides training on a specific task, lifelong environmental enrichment also has a positive impact on memory preservation, as well as on the maintenance of synapses and in the increase in number of newborn neurons within the hippocampus during aging (Leal-Galicia et al. 2008). This agrees with human epidemiological studies which suggest that an intellectually active life protects against cognitive disabilities seen at old age (Snowdon et al. 1996; Friedland et al. 2001; Wilson et al. 2002; Colcombe et al. 2004a,b). The "use it or lose it" concept states that neuronal activation may prevent neurodegeneration and strengthens connectivity (Swaab 1991). With (c)TPL training over the lifespan, this principle may apply to either or both the cognitive and circadian neuronal substrates underlying CTPL, or to interconnections between these neuronal substrates. We showed that short-term spatial working memory and motivation to explore a three-arm maze, as measured by the SA test, were not affected by aging. Untrained middle-aged mice showed similar performance as trained middle-aged mice, indicating that SA performance is not affected by previous training. SA performances were similar as found by others (Lamberty and Gower 1990, 1992; Naude et al. 2014).

\section{Memory preservation at old age: a sign of rigidity}

In contrast to TPL testing at all other ages, trained old mice did not show a learning curve, but immediate high TPL performance instead (Fig. 2C, LD1). Although low in number, these mice behaved very compliant in this (double) reinforced task. Apparently, the acquired time-place-event memories were preserved over a period of 3.1 mo since the last day of previous TPL testing. For comparison, the time between TPL testing at ages 4 - and 7-mo was only 1.7 mo. This excludes the possibility that the absence of a learning curve is the consequence of a shorter time between TPL experiments. It seems that the mice had developed an exceptionally good memory at old age. One consideration, however, is that the use of outdated information in an ever changing environment can be detrimental. Aged mice relying upon previously learned time-place contingencies would presumably have difficulties if the correct/incorrect location information was changed and fail to show TPL under changing conditions. It is unlikely that the observed preservation of TPL memory at old age is solely attributable to the extensive amount of training the mice had received at this age. In this case, we would have expected mice to demonstrate preservation of TPL memory at an earlier age. Note that mice had already been extensively tested for $109 \mathrm{~d}$ before being tested at middle-age, at which point they still showed a typical learning curve. The preservation of TPL memory in trained old mice more likely demonstrates aging-related behavioral rigidity. In line with this, behavioral rigidity (or "response perseveration," i.e., maintaining a trained behavioral response without assessing whether this response is still appropriate) has been a consistent finding in rodent studies examining aging-related changes in learning and memory abilities, especially in tasks that require aged subjects to adapt to novelty or to change a previously trained response (Goodrick 1975; Barnes et al. 1980; Dean et al. 1981; Vasquez et al. 1983; Stephens et al. 1985; Means and Holsten 1992; Havekes et al. 2011). Such behavioral rigidity, demonstrated by the absence of a learning curve, has not been reported before in the context of TPL.

\section{Hippocampal rigidity}

Behavioral rigidity may be a manifestation of rigidity at the level of neuronal memory networks, which become less plastic or susceptible to modification with aging. One of the sites that undergo the earliest changes with aging is the hippocampus, which has a well-known role in remembering events (Squire et al. 2004; Stranahan et al. 2008; Berke et al. 2009). Wilson et al. (2006) proposed that small concurrent changes during aging may strengthen the auto-associative network of the CA3 subregion at the cost of processing new information arising from the entorhinal cortex. As a result of such reorganization in aged memoryimpaired individuals, information that is already stored would become the dominant pattern of the hippocampus to the detriment of the ability to encode new information (Wilson et al. 2006). In line with this, electrophysiological recording studies in aged rodents have demonstrated rigidity in aged CA3 place cell firing patterns. Hippocampal place cells (a type of pyramidal neurons) become active when animals enter a particular place in the environment, known as the place field. Young CA3 place cells readily remap and shift their representations, while aged CA3 place cells retain their original fields despite changes in the environment (Wilson et al. 2006; Yassa et al. 2011). Next to place cells in the hippocampal CA1 and CA3 subregions, time cells have recently been identified, shown to track the elapsing of time (Macdonald et al. 2011; Shapiro 2011; Mankin et al. 2012). Given our data, it is tempting to speculate that such time cells participate in TPL memory networks and undergo similar rigidity with aging.

Besides age-related hippocampal deficiencies, behavioral rigidity may also be explained by the conception that over time memory traces become independent from the hippocampus and more dependent on the cortex (long-term memory storage) or striatum (if it becomes procedural) (Lehmann et al. 2009; Smith and Squire 2009; Kitamura and Inokuchi 2014). The necessary plasticity or circadian system connections required for cTPL may thereby be lost (Mulder et al. 2013b).

\section{Reduced behavioral flexibility at old age: inability to update time-of-day information}

When TPL testing of the old mice was continued in LL, mice showed a gradual decline in performance (Fig. 2C, LL1), which 
was confirmed by a second switch from LD to LL (Fig. 2C, LD2, LL2). One explanation for this effect may be that the signal of the internal clock is weaker or more distorted in LL. However, in this case we would expect a more immediate, rather than a gradual loss of performance in LL. Instead, the gradual performance loss in LL fits the conception of rigid memory in combination with a freerunning internal reference clock (-system). Without the presence of an entraining zeitgeber (i.e., in LL), circadian clocks will freerun, because the intrinsic period $(\tau)$ is slightly longer than 24 h. Moreover, our data show that $\tau$ slightly increases with age (Fig. 5B, bottom right graph showing $\tau$ with aging), which has been shown before in mice (Possidente et al. 1995; Mayeda et al. 1997; Valentinuzzi et al. 1997).

Unless the time stamps stored in memory (which are based on the previous entrained conditions in LD) are updated with daily testing relative to the free-running reference clock (in LL), there will be an increasing mismatch between the time stamps and the reference clock. We suspect that this progressive mismatch is the cause of the observed gradual performance loss in LL. Note that if time stamps are updated with daily testing (as presumably occurs in younger mice), the deviation between internal clock and time stamps remains limited to $1 \mathrm{~d}$ free-run shift and will not cause observable performance loss. Indeed, in a pilot experiment we previously found that TPL performance is not affected by small deviations from the routine testing times. As expected, mice will start making mistakes when the deviation approaches half of the intersession time (data not shown). The putative failure to update time stamps at the age of 22 mo is further supported by the immediate instead of gradual recovery of performance when we switched from LL back to LD (Fig. 2C, LD2). The absence of a learning curve here indicates that the old time stamps were still in place.

\section{TPL deficiencies occur at middle-age in untrained mice}

The inability of untrained middle-aged mice to acquire cTPL demonstrates that TPL deficiencies already occur around this relative young age. This corroborates with other studies showing that episodic spatial memory deficits emerge around middle-age (Markowska and Savonenko 2002; Bizon et al. 2009; Kumar and Foster 2013; Guidi et al. 2014). Untrained middle-aged mice showed lower performance in the third habituation step and generally TPL performance below chance level. Note that a session was considered correct, on an individual level, only when the two target locations were visited first, avoiding the nontarget location or visiting it last. Thus, if mice visited no location or only one in the given $8 \mathrm{~min}$, the session was considered failed. The lower performances were at least partly due to such response failure, but also because mice more frequently made incorrect location choices. Importantly, mice did not appear to be anxious or unmotivated in the TPL test, but were rather more hesitative (going in and out maze arms). This indicates uncertainty to make location choices, as would be expected with reduced TPL ability. Only healthy and vital (aged) mice were selected to be TPL tested. No signs of decreased motivation or motor skills were apparent from the SA test, in which the mice showed spatial working memory and exploratory behavior unaffected by aging. In the third habituation step, the nontarget location is shock-reinforced, but not baited, so that mice can discriminate the nontarget/target locations based on sensory perception of the absence/presence of food. However, mice cannot see the food, because it is placed in a small pocket behind the shocking grid. It is, therefore, most likely that mice use smell to identify the target locations in the third habituation step. Learning deficits in odor discrimination have been shown in aged rodents, and may thus explain the low performance in the third habituation step (LaSarge et al. 2007). This is, however, not a factor in subsequent TPL training, when all locations are baited and indistinguishable by odor.

\section{Switching strategies}

Two of the untrained middle-aged mice were able to master TPL. Session skipping indicated that these mice had adapted an alternative strategy that is independent of the circadian system. This supports a general theory of aging as a loss of behavioral and cognitive flexibility, in this case losing the ability to use the circadian strategy. To compensate performance loss, alternative strategies are explored. The striatum and hippocampus are widely held to be components of distinct memory systems that can guide competing behavioral strategies and compensate for each other in case of temporal or permanent damage (Becker et al. 1980; Packard et al. 1989; McDonald and White 1993; Berke et al. 2009). Multiple behavioral paradigms, like fear conditioning and various maze tasks have different versions which are either more hippocampal-dependent, or more dependent on other memory systems (e.g., striatum, amygdala, cortex) (for review, see Kennard and Woodruff-Pak 2011). A consistent finding in these studies is that the hippocampus-dependent version is more age-sensitive than the nonhippocampus-dependent version. Switches in learning strategy are also seen with sleep deprivation, which has adverse effects on hippocampus-dependent memory formation (Hagewoud et al. 2010; Havekes et al. 2011). We suspect that cTPL requires the plasticity of an intact hippocampus, while instead ordinal (noncircadian) TPL may depend more on a less age-sensitive memory system, presumably the striatum (Mulder et al. 2013b).

\section{Circadian system decline versus cognitive decline with age}

In line with other studies (Mayeda et al. 1997; Valentinuzzi et al. 1997; Antoniadis et al. 2000), we found severe declines in circadian activity parameters with aging (Fig. 5B). Note that for most of the analyzed parameters, a platform of decline is reached around middle-age (17-18 mo), matching the age at which untrained mice were unable to master cTPL. It is, however, not clear whether the observed decline in overt circadian activity parameters is representative for circadian system components underlying cTPL. Circadian rhythms in activity are mainly SCN driven, while we previously showed that the SCN is not required for CTPL (Mulder et al. 2014).

Although we excluded aging-related spatial working memory deficits in both trained and untrained mice, cTPL essentially requires spatial reference memory (i.e., the ability to remember reward locations across sessions). Note that this type of memory was still intact in the trained old mice (although presumably less plastic), as evidenced by the high performance in LD (Fig. 2C, LD1). Nevertheless, spatial reference memory could have been affected in the untrained middle-aged mice. We recently investigated spatial reference memory with aging using a complex maze (see Jónás et al. 2010 for a description of the maze), but found no differences in maze cross time or errors between young (3-6 mo old, $N=10)$, middle-aged (11-15 mo old, $N=10)$, and old (18-27 mo old, $N=13$ ) mice (EA Van der Zee and C Papantoniou, unpubl.). These mice had the same background, gender, and origin as the mice used for the TPL experiments. Moreover, mice are similarly motivated (food deprived) for both the complex maze and the TPL paradigm. Frick et al. (2000) used a Morris Water Maze setup to assess spatial reference memory in 5-, 17-, and 25-mo-old C57BL6 mice. The authors found deficiencies at the age of $25 \mathrm{mo}$, but not between 5- and 17-mo-old males (although moderate effects were found in females). Together these data suggest that spatial reference memory was 
intact in the untrained middle-aged mice. Nevertheless, we cannot conclude with certainty whether the CTPL inability of untrained middle-aged mice is attributable to either a deficiency of the circadian system or of spatial reference memory (or other cognitive factors), although for now the circadian system decline seems the most likely cause. Similarly, although the absence of a learning curve in trained old mice (Fig. 2C, LD1) suggests rigid memory, the putative failure to update time stamps (i.e., gradual performance loss in LL: Fig. 2C LL1, LL2) may also be explained in terms of circadian system decline, if the signal of the internal reference clock is too weak to update TPL time stamps.

Overall, we suspect that age-related deterioration of both the cognitive- and circadian system contribute to TPL deficiencies. This is especially likely given that recent studies suggest that these systems are highly integrated at the level of the hippocampus. The hippocampus presumably holds a central place in CTPL behavior, perhaps not only for the storage and retrieval of time-place associated memories, but also for harboring a local timekeeping mechanism. Clock genes are expressed in all subregions of the hippocampus and thought to support temporally regulated events underlying memory processes, such as acquisition, consolidation, and retrieval (Eckel-Mahan et al. 2008; Eckel-Mahan and Storm 2009; Gerstner et al. 2009; Gerstner and Yin 2010; Jilg et al. 2010; Kondratova et al. 2010; Rawashdeh and Stehle 2010; Kondratova and Kondratov 2012). In a pilot study, we found a $26 \%$ increase in CRY2 (the protein product of the core molecular clock gene Cry2) positive cells in the hippocampal dentate gyrus of TPL-trained mice compared with homecage control mice (data not included). In line with this, we previously showed that young-adult Cry1/Cry2 double knockout mice were unable to acquire TPL (Van der Zee et al. 2008). Therefore, we suspect that experience-related cues entrain local hippocampal timekeeping mechanisms that are functional to cTPL (Mulder et al. 2014). This supports the hypothesis that an aging-associated imbalance of rhythmic clock gene expressions in the hippocampus may be linked to age-associated deficiencies in cognitive tasks (Rawashdeh and Stehle 2010; Wyse and Coogan 2010).

Taken together, we found that spatial working memory and exploratory behavior remain intact with age, while circadian rhythms in overt behavior deteriorate with age. Trained old mice showed signs of behavioral rigidity by preservation of TPL memory over an extended period of time, in sharp contrast to testing at younger ages. In line with this, while maintaining a circadian TPL strategy, these mice showed reduced behavioral flexibility by a putative inability to update time-of-day information. Conversely, untrained middle-aged mice were incapable of acquiring (c)TPL, indicating that training had delayed TPL deficiencies in the mice trained over lifespan. Some untrained middle-aged mice buffered performance loss by adapting an alternative strategy that is independent of the circadian system, suggesting that cTPL is more age-sensitive than ordinal TPL. In line with other studies we hypothesize that age-related hippocampal dysfunction, together with age-related circadian system decline, induces a shift from using the hippocampal (declarative) memory system to relying more on the striatal (procedural) memory system. This hypothesis needs to be confirmed in future studies, for instance by selective lesions in the hippocampus and striatum.

\section{Materials and Methods}

\section{Animals and housing}

All experiments were performed using male C57BL6/J mice (Harlan, Horst, the Netherlands). All mice were housed individually in macrolon type II cages (length $35 \mathrm{~cm}$, width $15 \mathrm{~cm}$, height $13.5 \mathrm{~cm}$, Bayer), with sawdust as bedding and shredded cardboard as nesting material. The mice were kept in a climate room with controlled temperature $\left(22 \pm 1^{\circ} \mathrm{C}\right)$ and humidity $(55 \pm 10 \%)$. A light-dark (LD) schedule (12-h light-dark cycle; lights on at 7:00 a.m. GMT +1 h) was maintained, except in the constant light (LL) or constant dark (DD) conditions. Light intensity was always 20-50 lx measured between the cages. Food (standard rodent chow: RMHB/ 2180, Arie Block BV) was available ad libitum, except during food deprivation (TPL testing). Normal tap water was available ad libitum. Cages were cleaned at least once every $2 \mathrm{wk}$ and were enriched with a plastic running-wheel (diameter $13.5 \mathrm{~cm}$ ). Activity, measured by running-wheel revolutions per 2 min bins, was recorded continuously throughout the experiment, by a Circadian Activity Monitor System (CAMS by H.M. Cooper, JA Cooper, INSERM U846, Department of Chronobiology). All mice were checked daily for food/water/health/activity/abnormal behavior. All efforts were made to minimize animal suffering and to reduce the number of animals used. All procedures were in accordance with the regulation of the ethical committee for the use of experimental animals of the University of Groningen, The Netherlands (License number DEC 5583A/F).

\section{TPL test apparatus and procedures}

The used TPL test apparatus and testing procedures were described before (Van der Zee et al. 2008; Mulder et al. 2013a,b, 2014). Briefly, the TPL test apparatus consisted of a round middle chamber (diameter $12.5 \mathrm{~cm}$; height $7 \mathrm{~cm}$ ) made of gray PVC and a transparent Plexiglas lid with ventilation holes. Four round tubes (arms) made of transparent Plexiglas (length $24.5 \mathrm{~cm}$; inside diameter $4.5 \mathrm{~cm}$ ) were connected to this middle chamber. One bottom arm served as a starting point to which a small transport cage could be connected from which the mice could enter the maze. The other three upper arms $\left(60^{\circ}\right.$ apart $)$ were equipped with a small food platform (gray PVC; $1.0 \times 4.5 \mathrm{~cm})$ and a steel grid $(6 \times 3.5$ $\mathrm{cm}$ ) at the end through which a mild but aversive electric footshock could be delivered. In order to reach the food in the baited arms, the mice had to step onto the grid. The electric current could be manually delivered to each grid by pressing a button. This device was home-built at the University of Groningen (see Fig. 1 in Van der Zee et al. 2008).

To induce food seeking behavior and voluntary location choices, mice were food deprived to $85 \%$ of their ad libitum body weight, as individually determined by the average of three daily measurements prior to initiating food deprivation. To monitor body weight during testing, mice were weighed before being tested in each daily session and received an individual amount of food at the end of the light phase (ZT10.5). In each of three daily sessions (lasting maximally 10 min per mouse), TPL test mice had to learn to avoid one of the three presented feeding locations, depending on the time of day (i.e., session). On visiting the nontarget location, mice received a mild but aversive footshock (set to $620 \mathrm{~V} ; 0.09 \mathrm{~mA} ;<1 \mathrm{sec}$ ). A session was considered correct, on an individual level, only when the two target locations were visited first, avoiding the nontarget location or visiting it lastly. Daily performance was calculated for each animal as the percentage of correct sessions (e.g., $0 \%, 33 \%, 67 \%$, or $100 \%$ ) and these performances were averaged over all mice, forming a learning curve over multiple testing days. Before mice were tested for the first time, testing was preceded by $10 \mathrm{~d}$ of habituation steps as described previously (Van der Zee et al. 2008; Mulder et al. $2013 a, b, 2014)$. In short, during the first $4 \mathrm{~d}$ all locations were baited and safe to explore freely (no footshock delivery). During the next $3 \mathrm{~d}$ only the nontarget location was kept unbaited, but still safe to visit (no footshock delivery). During the following $3 \mathrm{~d}$, the shock was introduced at the nontarget location, while still kept unbaited, so that mice could identify the nontarget location based on sensory perception. After these habituation steps, actual TPL testing started with all locations baited and footshock delivery in the nontarget location. Hence, mice could not identify the nontarget/target location(s) based on sensory perception and had to use knowledge of circadian phase to discriminate the hazardous nontarget location. The same reward and shock positions were used in all TPL experiments and these were not 
randomized between individual mice. A schematic overview of the daily protocol is provided in Figure 1.

\section{Experimental outline}

A first group of mice $(N=8)$ was tested five times throughout their lifespan, each time under both a 12-h light-dark (LD) cycle, and under constant conditions (LL or DD). Five days before each TPL experiment (after taking ad libitum body weight measurements), the SA test was performed. Food deprivation (timed feeding) was started after the SA test (ad libitium food was removed and mice received a minimum of $1.5 \mathrm{~g}$ per day, at ZT 10.5). At 4 mo of age the mice were tested for the first time, starting with the habituation steps (10 d), followed by $24 \mathrm{~d}$ of TPL testing in LD (days 1$24)$, followed by $12 \mathrm{~d}$ of testing in LL (days 25-36). Session skips were performed on following TPL test days, with the number between brackets indicating which session was skipped: 12(2); 14(1); 19(2); 22(1); 26(1); 29(2); 31(3). Habituation steps were not repeated with following TPL experiments on this group of mice. Mice were TPL tested for the second time at 7 mo of age for $8 \mathrm{~d}$, starting with $6 \mathrm{~d}$ of testing in LD, followed by $2 \mathrm{~d}$ of testing in LL. A session was skipped on day 8(1). Mice were TPL tested for the third time at 12 mo of age for $55 \mathrm{~d}$, starting with $38 \mathrm{~d}$ of testing in $\mathrm{LD}$, followed by $16 \mathrm{~d}$ of testing in DD. Session skips were performed on days 14(1); 16(2); 22(1,2); 27(1,2,3); 52(1), 54(1). Mice were tested for the fourth time at 18 mo of age for $33 \mathrm{~d}$, starting with $22 \mathrm{~d}$ in LD, followed by $11 \mathrm{~d}$ in LL. Session skips were performed on days 5(1); 10(2); 30(1). Mice were tested for the fifth time at 22 mo of age for $22 \mathrm{~d}$, starting with $8 \mathrm{~d}$ in LD, followed by $6 \mathrm{~d}$ in LL, followed by $3 \mathrm{~d}$ in LD, followed by $5 \mathrm{~d}$ in LL. Session skips were performed on days 7(1); 18(1).

A second group of naïve middle-aged mice $(17$ mo old, $N=9)$ was tested, starting with the habituation steps, followed by $14 \mathrm{~d}$ of TPL testing in LD. Session skips were performed on TPL test days: 5(2); 8(1); 10(1); 13(2).

\section{Spontaneous alternation test}

Short-term spatial memory performance (working memory) was assessed by recording spontaneous alternation (SA) behavior in a Y-maze paradigm, as described before (Mulder et al. 2013a, 2014). The Y-maze consisted of three tubular and transparent Plexiglas arms (Evonik Industries AG) forming the Y. All three arms were $4.4 \mathrm{~cm}$ in internal diameter, $29 \mathrm{~cm}$ long, and at a $120^{\circ}$ angle from each other. The experimental room contained visual cues, which served as distal spatial cues. Mice were placed in the center of the Y-maze (5 cm internal diameter) and allowed to explore the maze freely during an 8-min session. The series of arm entries was recorded visually. An arm entry was considered to be complete when all four paws of the animal had entered a Y-maze arm. The maze was cleaned between each test with water and paper towels. An alternation is defined as successive entries into the three different maze arms. The alternation percentage (SA performance) was calculated as the ratio of actual to possible alternations (defined as the total number of arm entries minus two) (Anisman 1975). Exploratory behavior was assessed by counting the number of arm entries.

\section{Analysis of activity parameters}

Running-wheel data were structured in 10 min bins. Twenty LD periods, or data "blocks" (distributed over lifespan, when animals were not TPL tested) of $15 \mathrm{~d}$ each, were analyzed for daily activity, fragmentation, interdaily stability, signal-to-noise ratio, and amplitude. Similarly, five LL blocks of, respectively, 15, 12, 11, 15, and $12 \mathrm{~d}$ were analyzed for circadian period $(\tau)$ by $\chi^{2}$ periodogram analysis. Daily activity is the average daily activity per block, calculated for each mouse by summing all running-wheel revolutions per day and averaging per block. Fragmentation is a measure for the frequency of transitions between rest and activity. The fragmentation percentage can be calculated for each mouse and data block, by dividing the number of activity bouts (sequential active/nonzero data bins) by the total number of active data bins, times 100 to get a percentage. The relative amplitude of the rhythm was calculated from the most active $10 \mathrm{~h}$ period (M10) and the least active $5 \mathrm{~h}$ period (L5) in the average $24 \mathrm{~h}$ activity profile: Amplitude = [M10-L5] (Van Someren et al. 1999). The interdaily stability quantifies the invariability between the days, that is, the strength of coupling of the rhythm to supposedly stable environmental zeitgebers. It is the 24 -h value from the $\chi^{2}$ periodogram (Sokolove and Bushell 1978), normalized for the number of data, and can easily be calculated as the ratio between the variance of the average $24 \mathrm{~h}$ activity profile and the overall variance (see Van Someren et al. 1999 for the exact mathematical formula). The signal-to-noise ratio is a measure for the strength of the circadian rhythm relative to the noisiness within the data, where the signal is the average $24 \mathrm{~h}$ data profile, and the noise is the absolute difference between each data point and its corresponding value in the average $24 \mathrm{~h}$ activity profile. The signal-to-noise ratio is then calculated as the variation of the signal values divided by the variation of the noise values (Dowse and Ringo 1989; White et al. 1992). Period length in LL data blocks were assessed by $\chi^{2}$ periodogram analysis (Sokolove and Bushell 1978; Refinetti 2004). All parameters were analyzed using ACTOVIEW for Excel 2010, programmed by C. Mulder, University of Groningen (freely available on request), which was also used to create the averaged actogram.

\section{Statistics}

Repeated measurements of the SA test were analyzed using SigmaPlot 12.5 (Systat Software, Inc.). Differences from chance level were tested by two-tailed one-sample $t$-test (Statistix 8). Other statistics were performed using GraphPad Prism 5.01 (GraphPad software). The used statistical tests are indicated in the text. $P<0.05$ was considered significant.

\section{References}

Anisman H. 1975. Dissociation of disinhibitory effects of scopolamine: strain and task factors. Pharmacol Biochem Behav 3: 613-618.

Antoniadis EA, Ko CH, Ralph MR, McDonald RJ. 2000. Circadian rhythms, aging and memory. Behav Brain Res 114: 221-233.

Barnes CA, Nadel L, Honig WK. 1980. Spatial memory deficit in senescent rats. Can J Psychol 34: 29-39.

Becker JT, Walker JA, Olton DS. 1980. Neuroanatomical bases of spatial memory. Brain Res 200: 307-320.

Berke JD, Breck JT, Eichenbaum H. 2009. Striatal versus hippocampal representations during win-stay maze performance. J Neurophysiol 101: $1575-1587$.

Biebach H. 1989. Time-and-place learning by garden warblers, Sylvia borin. Anim Behav 37: 353-360.

Biemans BA, Van der Zee EA, Daan S. 2003. Age-dependent effects of conditioning on cholinergic and vasopressin systems in the rat suprachiasmatic nucleus. Biol Chem 384: 729-736.

Bizon JL, LaSarge CL, Montgomery KS, McDermott AN, Setlow B, Griffith WH. 2009. Spatial reference and working memory across the lifespan of male Fischer 344 rats. Neurobiol Aging 30: 646-655.

Blokland A, Sik A, van der Staay FJ. 2004. Delayed non-matching to position performance in aged hybrid Fischer $344 \mathrm{x}$ brown Norway rats: a longitudinal study. Brain Res Bull 64: 39-46.

Brown SA, Pagani L, Cajochen C, Eckert A. 2011. Systemic and cellular reflections on ageing and the circadian oscillator: a mini-review. Gerontology 57: 427-434.

Burke SN, Barnes CA. 2006. Neural plasticity in the ageing brain. Nat Rev Neurosci 7: 30-40.

Cain SW, Karatsoreos I, Gautam N, Konar Y, Funk D, McDonald RJ, Ralph MR. 2004. Blunted cortisol rhythm is associated with learning impairment in aged hamsters. Physiol Behav 82: 339-344.

Carr JA, Wilkie DM. 1997. Rats use an ordinal timer in a daily time-place learning task. J Exp Psychol Anim Behav Process 23: 232-247.

Carr JAR, Wilkie DM. 1999. Rats are reluctant to use circadian timing in a daily time-place task. Behav Processes 44: 287-299.

Carr JAR, Tan AO, Wilkie DM. 1999. Further evidence that rats use ordinal timing in a daily time-place learning task. Behav Processes 48: $35-48$.

Colcombe SJ, Kramer AF, Erickson KI, Scalf P, McAuley E, Cohen NJ, Webb A, Jerome GJ, Marquez DX, Elavsky S. 2004a. Cardiovascular fitness, cortical plasticity, and aging. Proc Natl Acad Sci 101: 3316-3321. 
Colcombe SJ, Kramer AF, McAuley E, Erickson KI, Scalf P. 2004b. Neurocognitive aging and cardiovascular fitness: recent findings and future directions. J Mol Neurosci 24: 9-14.

Dean RL III, Scozzafava J, Goas JA, Regan B, Beer B, Bartus RT. 1981. Age-related differences in behavior across the life span of the C57BL/6J mouse. Exp Aging Res 7: 427-451.

Dibner C, Schibler U, Albrecht U. 2010. The mammalian circadian timing system: organization and coordination of central and peripheral clocks. Annu Rev Physiol 72: 517-549.

Dowse HB, Ringo JM. 1989. The search for hidden periodicities in biological time series revisited. J Theor Biol 139: 487-515.

Eckel-Mahan KL, Storm DR. 2009. Circadian rhythms and memory: not so simple as cogs and gears. EMBO Rep 10: 584-591.

Eckel-Mahan KL, Phan T, Han S, Wang H, Chan GC, Scheiner ZS Storm DR. 2008. Circadian oscillation of hippocampal MAPK activity and cAmp: implications for memory persistence. Nat Neurosci 11: 1074-1082.

Enright JT. 1970. Ecological aspects of endogenous rhythmicity. Annu Rev Ecol Syst 1: 221-238.

Falk H. 1992. Learning a time-place pattern of food availability. Behav Ecol Sociobiol 31: 9-15.

Fleischman DA, Wilson RS, Gabrieli JD, Bienias JL, Bennett DA. 2004. A longitudinal study of implicit and explicit memory in old persons. Psychol Aging 19: 617-625.

Frick KM, Burlingame LA, Arters JA, Berger-Sweeney J. 2000. Reference memory, anxiety and estrous cyclicity in C57BL/6NIA mice are affected by age and sex. Neuroscience 95: 293-307.

Friedland RP, Fritsch T, Smyth KA, Koss E, Lerner AJ, Chen CH, Petot GJ, Debanne SM. 2001. Patients with Alzheimer's disease have reduced activities in midlife compared with healthy control-group members. Proc Natl Acad Sci 98: 3440-3445.

Gallistel CR. 1990. Representations in animal cognition: an introduction. Cognition 37: 1-22.

Gerstner JR, Yin JC. 2010. Circadian rhythms and memory formation. Nat Rev Neurosci 11: 577-588.

Gerstner JR, Lyons LC, Wright KP Jr, Loh DH, Rawashdeh O, Eckel-Mahan KL, Roman GW. 2009. Cycling behavior and memory formation. J Neurosci 29: 12824-12830.

Goodrick CL. 1975. Behavioral rigidity as a mechanism for facilitation of problem solving for aged rats. J Gerontol 30: 181-184.

Groos G, Hendriks J. 1982. Circadian rhythms in electrical discharge of rat suprachiasmatic neurones recorded in vitro. Neurosci Lett 34: 283-288.

Guidi M, Kumar A, Rani A, Foster TC. 2014. Assessing the emergence and reliability of cognitive decline over the life span in Fisher 344 rats using the spatial water maze. Front Aging Neurosci 6: 2.

Hagewoud R, Havekes R, Tiba PA, Novati A, Hogenelst K, Weinreder P, Van der Zee EA, Meerlo P. 2010. Coping with sleep deprivation: shifts in regional brain activity and learning strategy. Sleep 33: 1465-1473.

Hansalik M, Skalicky M, Viidik A. 2006. Impairment of water maze behaviour with ageing is counteracted by maze learning earlier in life but not by physical exercise, food restriction or housing conditions. Exp Gerontol 41: $169-174$.

Havekes R, Abel T, Van der Zee EA. 2011. The cholinergic system and neostriatal memory functions. Behav Brain Res 221: 412-423.

Hedden T, Gabrieli JD. 2004. Insights into the ageing mind: a view from cognitive neuroscience. Nat Rev Neurosci 5: 87-96.

Hofman MA, Swaab DF. 2006. Living by the clock: the circadian pacemaker in older people. Ageing Res Rev 5: 33-51.

Hut RA, Beersma DG. 2011. Evolution of time-keeping mechanisms: early emergence and adaptation to photoperiod. Philos Trans R Soc Lond B Biol Sci 366: 2141-2154.

Hut RA, Van der Zee EA. 2011. The cholinergic system, circadian rhythmicity, and time memory. Behav Brain Res 221: 466-480.

Hut RA, Paolucci S, Dor R, Kyriacou CP, Daan S. 2013. Latitudinal clines: an evolutionary view on biological rhythms. Proc Biol Sci 280: 20130433.

Jilg A, Lesny S, Peruzki N, Schwegler H, Selbach O, Dehghani F, Stehle JH. 2010. Temporal dynamics of mouse hippocampal clock gene expression support memory processing. Hippocampus 20: 377-388.

Jónás I, Schubert KA, Reijne AC, Scholte J, Garland T Jr, Gerkema MP, Scheurink AJ, Nyakas C, van Dijk DG. 2010. Behavioral traits are affected by selective breeding for increased wheel-running behavior in mice. Behav Genet 40: 542-550.

Kennard JA, Woodruff-Pak DS. 2011. Age sensitivity of behavioral tests and brain substrates of normal aging in mice. Front Aging Neurosci 3: 9.

Kitamura T, Inokuchi K. 2014. Role of adult neurogenesis in hippocampal-cortical memory consolidation. Mol Brain 7: 13.

Kondratova AA, Kondratov RV. 2012. The circadian clock and pathology of the ageing brain. Nat Rev Neurosci 13: 325-335.

Kondratova AA, Dubrovsky YV, Antoch MP, Kondratov RV. 2010. Circadian clock proteins control adaptation to novel environment and memory formation. Aging (Albany NY) 2: 285-297.
Kumar A, Foster TC. 2013. Linking redox regulation of NMDAR synaptic function to cognitive decline during aging. J Neurosci 33: $15710-15715$.

Lamberty Y, Gower AJ. 1990. Age-related changes in spontaneous behavior and learning in NMRI mice from maturity to middle age. Physiol Behav 47: $1137-1144$.

Lamberty Y, Gower AJ. 1992. Age-related changes in spontaneous behavior and learning in NMRI mice from middle to old age. Physiol Behav 51: $81-88$.

LaSarge CL, Montgomery KS, Tucker C, Slaton GS, Griffith WH, Setlow B, Bizon JL. 2007. Deficits across multiple cognitive domains in a subset of aged Fischer 344 rats. Neurobiol Aging 28: 928-936.

Leal-Galicia P, Castaneda-Bueno M, Quiroz-Baez R, Arias C. 2008. Long-term exposure to environmental enrichment since youth prevents recognition memory decline and increases synaptic plasticity markers in aging. Neurobiol Learn Mem 90: 511-518.

Lehmann H, Sparks FT, Spanswick SC, Hadikin C, McDonald RJ, Sutherland RJ. 2009. Making context memories independent of the hippocampus. Learn Mem 16: 417-420.

Macdonald CJ, Lepage KQ, Eden UT, Eichenbaum H. 2011. Hippocampal "time cells" bridge the gap in memory for discontiguous events. Neuron 71: $737-749$

Mankin EA, Sparks FT, Slayyeh B, Sutherland RJ, Leutgeb S, Leutgeb JK. 2012. Neuronal code for extended time in the hippocampus. Proc Natl Acad Sci 109: 19462-19467.

Markowska AL, Savonenko AV. 2002. Protective effect of practice on cognition during aging: implications for predictive characteristics of performance and efficacy of practice. Neurobiol Learn Mem 78: 294-320.

Mayeda AR, Hofstetter JR, Possidente B. 1997. Aging lengthens $\tau$ DD in C57BL/6J, DBA/2J, and outbred SWR male mice (Mus musculus). Chronobiol Int 14: 19-23.

McDonald RJ, White NM. 1993. A triple dissociation of memory systems: hippocampus, amygdala, and dorsal striatum. Behav Neurosci 107: $3-22$.

Means LW, Holsten RD. 1992. Individual aged rats are impaired on repeated reversal due to loss of different behavioral patterns. Physiol Behav 52: 959-963.

Mistlberger RE, de Groot MH, Bossert JM, Marchant EG. 1996. Discrimination of circadian phase in intact and suprachiasmatic nuclei-ablated rats. Brain Res 739: 12-18.

Mulder C, Van der Zee EA, Hut RA, Gerkema MP. 2013a. Time-place learning and memory persist in mice lacking functional per1 and per2 clock genes. J Biol Rhythms 28: 367-379.

Mulder CK, Gerkema MP, Van der Zee EA. 2013b. Circadian clocks and memory: time-place learning. Front Mol Neurosci 6: 8.

Mulder CK, Papantoniou C, Gerkema MP, Van der Zee EA. 2014. Neither the SCN nor the adrenals are required for circadian time-place learning in mice. Chronobiol Int 31: 1075-1092.

Naude PJ, Dobos N, van der Meer D, Mulder C, Pawironadi KG, den Boer JA, Van der Zee EA, Luiten PG, Eisel UL. 2014. Analysis of cognition, motor performance and anxiety in young and aged tumor necrosis factor alpha receptor 1 and 2 deficient mice. Behav Brain Res 258: 43-51.

Newman MC, Kaszniak AW. 2000. Spatial memory and aging: performance on a human analog of the morris water maze. Aging Neuropsychol Cogn 7: 86-93.

Nilsson LG. 2003. Memory function in normal aging. Acta Neurol Scand Suppl 179: 7-13.

Packard MG, Hirsh R, White NM. 1989. Differential effects of fornix and caudate nucleus lesions on two radial maze tasks: evidence for multiple memory systems. J Neurosci 9: 1465-1472.

Panda S, Hogenesch JB, Kay SA. 2002. Circadian rhythms from flies to human. Nature 417: 329-335.

Pizzo MJ, Crystal JD. 2002. Representation of time in time-place learning. Anim Learn Behav 30: 387-393.

Pizzo MJ, Crystal JD. 2004. Evidence for an alternation strategy in time-place learning. Behav Processes 67: 533-537.

Possidente B, McEldowney S, Pabon A. 1995. Aging lengthens circadian period for wheel-running activity in C57BL mice. Physiol Behav 57: $575-579$.

Ralph MR, Foster RG, Davis FC, Menaker M. 1990. Transplanted suprachiasmatic nucleus determines circadian period. Science 247: 975-978

Rawashdeh O, Stehle JH. 2010. Ageing or NOT, clock genes are important for memory processes: an interesting hypothesis raising many questions. Aging (Albany NY) 2: 259-260.

Refinetti R. 2004. Non-stationary time series and the robustness of circadian rhythms. J Theor Biol 227: 571-581.

Saksida L, Wilkie D. 1994. Time-of-day discrimination by pigeons, Columba livia. Anim Learn Behav 22: 143-154.

Shapiro ML. 2011. Memory time. Neuron 71: 571-573. 
Smith CN, Squire LR. 2009. Medial temporal lobe activity during retrieval of semantic memory is related to the age of the memory. J Neurosci 29: $930-938$.

Snowdon DA, Kemper SJ, Mortimer JA, Greiner LH, Wekstein DR, Markesbery WR. 1996. Linguistic ability in early life and cognitive function and Alzheimer's disease in late life. Findings from the Nun Study. J Am Med Assoc 275: 528-532.

Sokolove PG, Bushell WN. 1978. The $\chi^{2}$ periodogram: its utility for analysis of circadian rhythms. J Theor Biol 72: 131-160.

Squire LR, Stark CE, Clark RE. 2004. The medial temporal lobe. Annu Rev Neurosci 27: 279-306.

Stephan FK, Zucker I. 1972. Circadian rhythms in drinking behavior and locomotor activity of rats are eliminated by hypothalamic lesions. Proc Natl Acad Sci 69: 1583-1586.

Stephens DN, Weidmann R, Quartermain D, Sarter M. 1985. Reversal learning in senescent rats. Behav Brain Res 17: 193-202.

Stranahan AM, Lee K, Mattson MP. 2008. Contributions of impaired hippocampal plasticity and neurodegeneration to age-related deficits in hormonal pulsatility. Ageing Res Rev 7: 164-176.

Swaab DF. 1991. Brain aging and Alzheimer's disease, "wear and tear" versus "use it or lose it". Neurobiol Aging 12: 317-324.

Thorpe CM, Bates ME, Wilkie DM. 2003. Rats have trouble associating all three parts of the time-place-event memory code. Behav Processes 63: $95-110$.

Turek FW, Penev P, Zhang Y, van Reeth O, Zee P. 1995. Effects of age on the circadian system. Neurosci Biobehav Rev 19: 53-58.

Valentinuzzi VS, Scarbrough K, Takahashi JS, Turek FW. 1997. Effects of aging on the circadian rhythm of wheel-running activity in C57BL/6 mice. Am J Physiol 273: R1957-R1964.

Van der Zee EA, Jansen K, Gerkema MP. 1999. Severe loss of vasopressin-immunoreactive cells in the suprachiasmatic nucleus of aging voles coincides with reduced circadian organization of running wheel activity. Brain Res 816: 572-579.

Van der Zee EA, Havekes R, Barf RP, Hut RA, Nijholt IM, Jacobs EH, Gerkema MP. 2008. Circadian time-place learning in mice depends on Cry genes. Curr Biol 18: 844-848.

Van der Zee EA, Boersma GJ, Hut RA. 2009. The neurobiology of circadian rhythms. Curr Opin Pulm Med 15: 534-539. van Groen T, Kadish I, Wyss JM. 2002. Old rats remember old tricks; memories of the water maze persist for 12 months. Behav Brain Res 136: $247-255$.

Van Someren EJ, Swaab DF, Colenda CC, Cohen W, McCall WV, Rosenquist PB. 1999. Bright light therapy: improved sensitivity to its effects on rest-activity rhythms in Alzheimer patients by application of nonparametric methods. Chronobiol Int 16: 505-518.

Vasquez BJ, Martinez JL Jr, Jensen RA, Messing RB, Rigter H, McGaugh JL. 1983. Learning and memory in young and aged Fischer 344 rats. Arch Gerontol Geriatr 2: 279-291.

Weinert D. 2000. Age-dependent changes of the circadian system. Chronobiol Int 17: 261-283.

Wenger D, Biebach H, Krebs JR. 1991. Free-running circadian rhythm of a learned feeding pattern in starlings. Naturwissenschaften 78: 87-89.

White L, Ringo J, Dowse H. 1992. A circadian clock of Drosophila: effects of deuterium oxide and mutations at the period locus. Chronobiol Int 9: $250-259$

Wilson RS, Mendes De Leon CF, Barnes LL, Schneider JA, Bienias JL, Evans DA, Bennett DA. 2002. Participation in cognitively stimulating activities and risk of incident Alzheimer disease. J Am Med Assoc 287: $742-748$.

Wilson IA, Gallagher M, Eichenbaum H, Tanila H. 2006. Neurocognitive aging: prior memories hinder new hippocampal encoding. Trends Neurosci 29: 662-670.

Winocur G. 1992. Conditional learning in aged rats: evidence of hippocampal and prefrontal cortex impairment. Neurobiol Aging 13: $131-135$.

Wyse CA, Coogan AN. 2010. Impact of aging on diurnal expression patterns of CLOCK and BMAL1 in the mouse brain. Brain Res 1337: $21-31$.

Yassa MA, Mattfeld AT, Stark SM, Stark CE. 2011. Age-related memory deficits linked to circuit-specific disruptions in the hippocampus. Proc Natl Acad Sci 108: 8873-8878.

Received October 23, 2014; accepted in revised form March 16, 2015. 


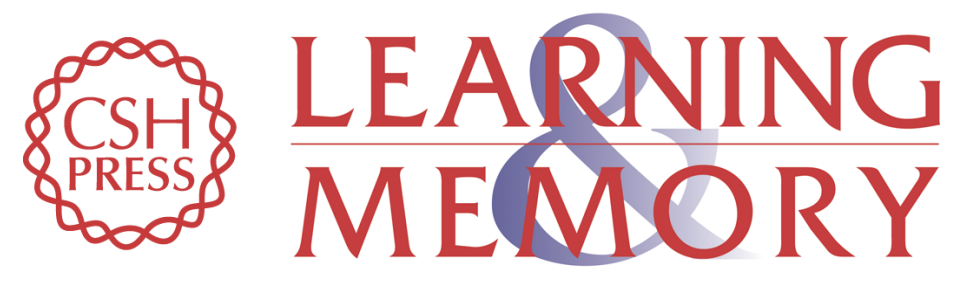

\section{Time-place learning over a lifetime: absence of memory loss in trained old mice}

Cornelis K. Mulder, Gerlof A.R. Reckman, Menno P. Gerkema, et al.

Learn. Mem. 2015, 22:

Access the most recent version at doi:10.1101/Im.037440.114

References This article cites 101 articles, 12 of which can be accessed free at: http://learnmem.cshlp.org/content/22/5/278.full.html\#ref-list-1

Creative This article is distributed exclusively by Cold Spring Harbor Laboratory Press for the Commons License first 12 months after the full-issue publication date (see

http://learnmem.cshlp.org/site/misc/terms.xhtml). After 12 months, it is available under a Creative Commons License (Attribution-NonCommercial 4.0 International), as described at http://creativecommons.org/licenses/by-nc/4.0/.

Email Alerting Receive free email alerts when new articles cite this article - sign up in the box at the Service top right corner of the article or click here. 